\title{
Experimental estimates of in-plane thermal conductivity in FePt-C granular thin film heat assisted magnetic recording media using a model layered system
}

\author{
Hoan Ho, ${ }^{1, a)}$ Abhishek A. Sharma, ${ }^{1}$ Wee-Liat Ong, ${ }^{2}$ Jonathan A. Malen, ${ }^{2}$ James A. Bain, ${ }^{1}$ \\ and Jian-Gang Zhu ${ }^{1}$ \\ ${ }^{1}$ Data Storage Systems Center, Carnegie Mellon University, Pittsburgh, Pennsylvania 15213, USA \\ ${ }^{2}$ Department of Mechanical Engineering, Carnegie Mellon University, Pittsburgh, Pennsylvania 15213, USA
}

(Received 2 August 2013; accepted 6 September 2013; published online 23 September 2013)

\begin{abstract}
Cross-plane thermal conductivity $k_{\mathrm{th}}$ measurements of vertical stacks of $\mathrm{FePt} / \mathrm{C}$ were used to estimate the in-plane thermal conductivity of Heat Assisted Magnetic Recording (HAMR) media that consist of columnar FePt grains segregated by thin $\mathrm{C}$ grain boundaries. FePt/C multilayers with varied repeat units and FePt layer thicknesses (chosen to represent HAMR media grain sizes) were measured using Frequency-Domain Thermoreflectance to determine $k_{\text {th }}$ in the direction normal to the layers. The data suggest that when FePt grains are less than $8 \mathrm{~nm}$ in diameter, the inplane $k_{\text {th }}$ for HAMR media is below $1 \mathrm{~W} / \mathrm{m}-\mathrm{K}$ and the anisotropy of $k_{\text {th }}$ (cross-plane/in-plane) will exceed 10. (C) 2013 AIP Publishing LLC. [http://dx.doi.org/10.1063/1.4821950]
\end{abstract}

Heat Assisted Magnetic Recording (HAMR) is a leading candidate for the next generation hard disk drive. ${ }^{1-4}$ The main technological difference between HAMR and conventional perpendicular magnetic recording (PMR) lies in the writing process, which involves local heating to beyond the Curie temperature $T_{C}$ using light, followed by rapid cooling in the presence of the applied head field to switch the magnetization. HAMR can solve the technology trilemma that PMR is now facing. ${ }^{5}$ With high magnetocrystalline anisotropy $\mathrm{L}_{0} \mathrm{FePt}$, media overcome the super-paramagnetic limit, while local heating to reduce the anisotropy field during the writing process overcomes the write field limitations. The effective write field gradient, which must be high to minimize medium noise, is contributed by the gradient of the anisotropy field versus temperature near $T_{C}$ of FePt, and the spatial gradient of temperature in the vicinity of the heat spot. ${ }^{5}$ Hence, understanding the thermal conductivity of FePt thin films is central to obtaining the proper thermal profile during writing. ${ }^{6-8}$

FePt magnetic media are typically sputtered with amorphous segregant such as $\mathrm{C}^{9-11}$ to produce small and isolated grains. Plan-view and cross-sectional Transmission Electron Microscope (TEM) images of FePt granular media with about $15 \mathrm{~nm}$ grain size are shown in Fig. 1(a). In this granular structure, the in-plane thermal conductivity is expected to be smaller than the cross-plane thermal conductivity because phonons and electrons that carry heat are scattered at the segregant interfaces between FePt grains ${ }^{12}$ as illustrated in Figure 1(b). Fernandez et al. ${ }^{13}$ investigated the overall crossplane thermal resistance of layered magnetic structures including FePt films on underlayers and heat sink layers. Measurement of in-plane thermal conductivity, on the other hand, is extremely challenging, when it is low, as it is in these films, because cross-plane thermal conduction paths into the underlayers or substrate dominate the measurement. ${ }^{14,15}$ In this paper, we present an experimental approach

${ }^{a)}$ Electronic mail: hoanh@andrew.cmu.edu that allows us to estimate the in-plane thermal conductivity in FePt granular thin films, by making a measurement on an experimental model system that avoids parallel thermal conduction pathways.

The model system consists of FePt and $\mathrm{C}$ multilayer stacks whose vertical heat conduction gives insight into the lateral thermal conduction in a real granular medium layer. The thermal conductivities of the film stacks in the direction normal to the layers were characterized using the FrequencyDomain Thermoreflectance (FDTR) technique, ${ }^{16-19}$ as illustrated in Figure 1(c), and we take those to be representative of the in-plane thermal conductivity of granular films when the lateral grain size is similar to the FePt thickness in the model samples. To estimate the effect of media grain size on the inplane lateral thermal conduction, the thickness of FePt layer was varied from $14.5 \mathrm{~nm}$ to $29 \mathrm{~nm}$. The C layer thickness, which represents grain boundary thickness, was fixed at $1 \mathrm{~nm}$.

The film stacks were fabricated by RF sputtering from $\mathrm{Fe}_{52.5} \mathrm{Pt}_{47.5}$ and $\mathrm{C}$ targets at a base pressure of better than $2 \times 10^{-7}$ Torr. To measure the thermal conductivity of the stack, the multilayer FePt/C film was deposited onto a 1 in. phosphorous-doped $\mathrm{Si}$ wafer and capped by a sputtered $\mathrm{Au}$ layer $(43 \mathrm{~nm})$ with a thin $\mathrm{Ti}$ adhesion layer $(2 \mathrm{~nm})$. The $\mathrm{Si}$ wafer was cleaned with buffered HF to remove the native oxide layer before entering the vacuum chamber. The Au top layer both absorbs light and acts as a reflectance-based thermometer for the FDTR measurements. FePt and $\mathrm{C}$ layers were deposited at an Ar pressure of 25 mTorr, room temperature, and a power of $50 \mathrm{~W}$ and $150 \mathrm{~W}$, respectively. ${ }^{20}$ Two sets of samples with varying number of $\mathrm{FePt} / \mathrm{C}$ repeated units and different FePt layer thicknesses were made:

(1) $\mathrm{Si} /\left[\mathrm{FePt}_{14.5 \mathrm{~nm}} / \mathrm{C}_{1 \mathrm{~nm}}\right]_{\mathrm{N}} / \mathrm{FePt}_{14.5 \mathrm{~nm}} / \mathrm{Au}(\mathrm{N}=1,2,3,5$, and 10) which are notated as $1 \mathrm{~N} 1,1 \mathrm{~N} 2,1 \mathrm{~N} 3,1 \mathrm{~N} 5$, and $1 \mathrm{~N} 10$ and (2) $\mathrm{Si} /\left[\mathrm{FePt}_{29 \mathrm{~nm}} / \mathrm{C}_{1 \mathrm{~nm}}\right]_{\mathrm{N}} / \mathrm{FePt}_{29 \mathrm{~nm}} / \mathrm{Au}(\mathrm{N}=1,5$, and 10) which are notated as $2 \mathrm{~N} 1,2 \mathrm{~N} 5$, and $2 \mathrm{~N} 10$. The crosssectional TEM images in Figures 2(d)-2(f) show that the periodic structures of $1 \mathrm{~N} 3,1 \mathrm{~N} 10$, and $2 \mathrm{~N} 10$ have welldefined FePt and $\mathrm{C}$ layers. 


\section{FePt Granular Media}

(a)
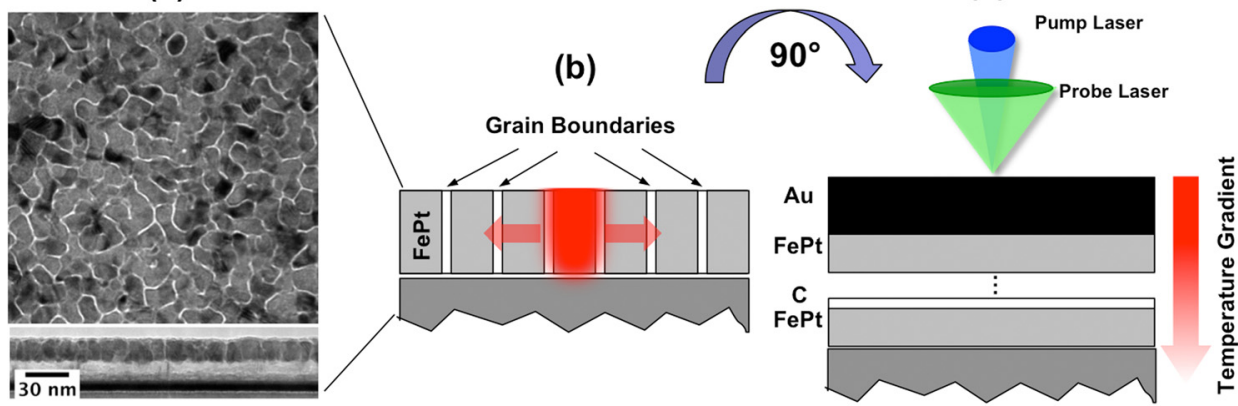

TEM Images

(d) $[\mathrm{FePt} / \mathrm{C}]_{3} \mathrm{FePt}(14.5 \mathrm{~nm})$

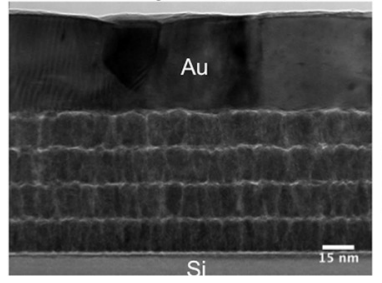

(e) $[\mathrm{FePt} / \mathrm{C}]_{10} \mathrm{FePt}(14.5 \mathrm{~nm})$

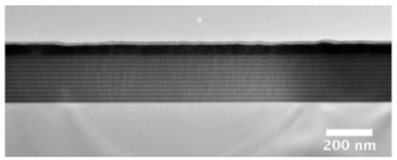

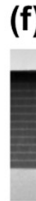

FIG. 1. (a) Plan-view and crosssectional TEM images of FePt granular media; (b) Schematic of heat conduction in granular media; (c) Structure of $\mathrm{FePt} / \mathrm{C}$ model system (the laser beams are not drawn to scale); and crosssection TEM images of (d) $1 \mathrm{~N} 3$, (e) $1 \mathrm{~N} 10$, and (f) $2 \mathrm{~N} 10$.
In the FDTR method, ${ }^{16,18,19}$ schematically illustrated in Figure 2(a), two continuous wave lasers periodically heat the sample and measure its thermal response to determine the unknown thermal transport properties of the $\mathrm{FePt} / \mathrm{C}$ stack. The $1 / \mathrm{e}^{2}$ effective radius of the Gaussian laser spots on the sample surface was measured by knife-edge to be $2.6 \pm 0.2 \mu \mathrm{m}$. The pump laser $(488 \mathrm{~nm})$ was intensity modulated by an electro-optic modulator and heated the Au top layer over a range of frequencies from $100 \mathrm{kHz}$ to $20 \mathrm{MHz}$. The periodic temperature change of the sample was continuously monitored by the probe laser $(532 \mathrm{~nm})$ through the temperature dependent reflectivity of the $\mathrm{Au}$ surface. The resultant probe signal measured by a photodiode was analyzed using an RF lock-in amplifier to generate frequencydependent phase lag of temperature change relative to the heat flux. The unknown thermal conductivity of materials of interest was then obtained by fitting these phase data to an analytical solution of the diffusive heat conduction equation. $^{21}$ The unknown fitting parameters were the effective thermal conductivity of the FePt/C stack and $\mathrm{Si}$ substrates. As input to the fitting program, the layer thicknesses were measured from the cross section TEM images. Likewise, the $k_{t h}$ values of Au were calculated from the Au sheet resistance as measured by 4-point probe measurements for separate $\mathrm{Au}$ films deposited on $1 \mu$ m-thick thermally grown $\mathrm{SiO}_{2}$ films on Si substrates following the Weidemann Franz Law. The $k_{t h}$ value of n-type Si substrates were found to be $95 \pm 10 \mathrm{~W} / \mathrm{m}$ $\mathrm{K}$, which appears low relative to the bulk value $(143 \mathrm{~W} / \mathrm{m}-\mathrm{K})$ for $\mathrm{Si}$, but is reasonably attributed to the known suppression in $k_{t h}$ observed by high frequency FDTR measurements ${ }^{17,18}$ paired with effects of added phonon scattering due to phosphorous dopant concentration of about $10^{15} \mathrm{~cm}^{-3}$ (Ref. 22). The mass density, $\rho$, values of $\mathrm{FePt} / \mathrm{C}$ film stacks were an average of mass density of $\mathrm{Fe}_{52.5} \mathrm{Pt}_{47.5}\left(15028 \mathrm{~kg} / \mathrm{m}^{3}\right)$ (Refs. 23 (a)

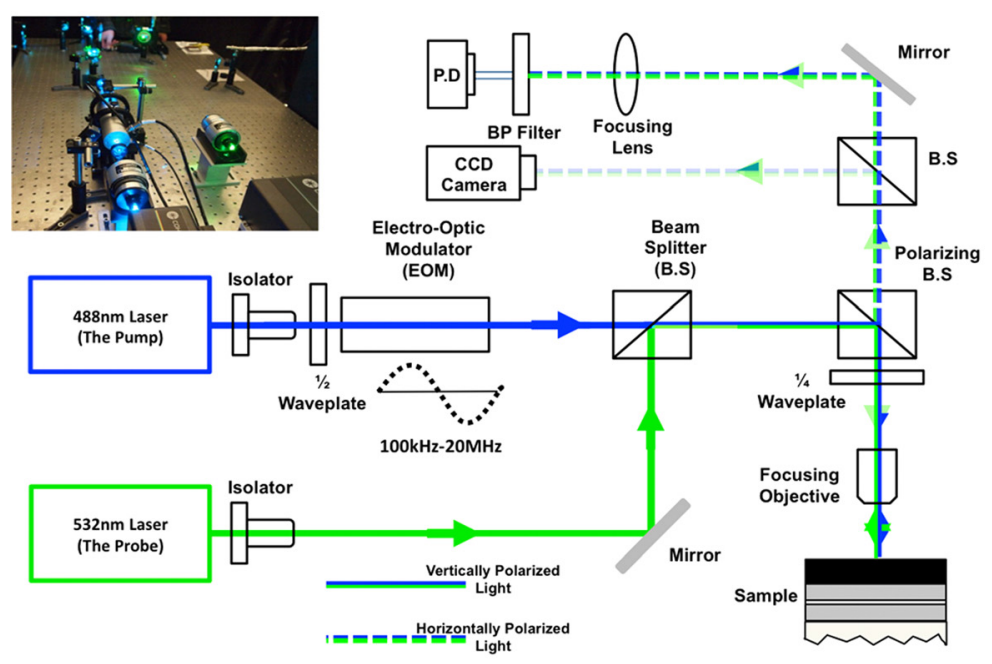

(b)

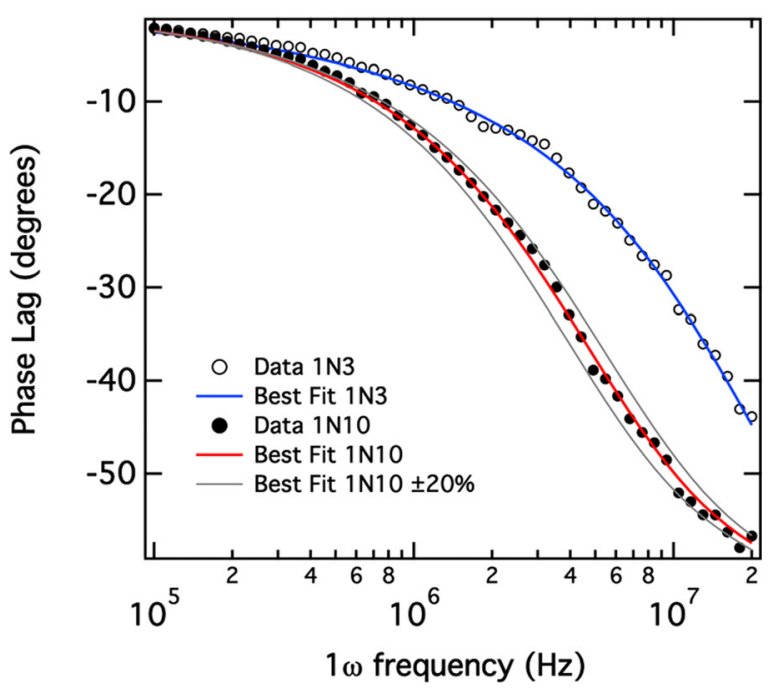

FIG. 2. (a) Schematic illustration of FDTR set up, (b) Phase data and fitting curves of $1 \mathrm{~N} 3$ and $1 \mathrm{~N} 10$ against the modulation frequency. 
and 24) and amorphous C (1950 kg/m³) (Ref. 25) by thickness percentage. The heat capacity values, $C_{p}$, of the FePt/C film stacks were taken to be an average of the mass heat capacity of $\mathrm{Fe}_{52.5} \mathrm{Pt}_{47.5}(207 \mathrm{~J} / \mathrm{kg}-\mathrm{K})$ (Ref. 23 and 24) and amorphous C (450 J/kg-K) (Ref. 26) by weight percentage.

Figure 2(b) is two sets of phase lag data of the temperature change in the Au layer as a function of laser-intensitymodulation frequency for samples $1 \mathrm{~N} 3$ and $1 \mathrm{~N} 10$. Best fitting curves give the $k_{t h}$ values of $1.30 \mathrm{~W} / \mathrm{m}-\mathrm{K}$ and $1.56 \mathrm{~W} / \mathrm{m}-\mathrm{K}$ for $1 \mathrm{~N} 3$ and $1 \mathrm{~N} 10$, respectively. The thermal conductivities $k_{t h}$ and thicknesses $L$ of the $[\mathrm{FePt} / \mathrm{C}]_{\mathrm{N}} / \mathrm{FePt}$ film stacks are listed in Table I. These values were averaged over 3 measurements at 3 locations on the samples. The reported uncertainty was estimated following the uncertainty analysis described elsewhere $^{16}$ assuming $\pm 2 \%$ uncertainties in the value of $\rho, C_{p}$, and thickness of the $\mathrm{Au}$ layer, $[\mathrm{FePt} / \mathrm{C}]_{\mathrm{N}} / \mathrm{FePt}$ stack and $\mathrm{Si}$ substrate; $\pm 5 \%$ uncertainty in the $k_{t h}$ of the Au layer; and $\pm 10 \%$ in the $k_{t h}$ of the Si substrate and laser spot size. The resulting thermal conductivities have uncertainties of $4 \%-12 \%$. The thermal conductivity extracted from the fit includes the interfacial thermal conductance of $\mathrm{Au}$ and $\mathrm{Si}$ as part of the bulk layered stack. To separate out these interface contributions, the thermal resistance of the samples, $R_{t h}=L / k_{t h}$, was plotted versus the number of $\mathrm{FePt} / \mathrm{C}$ repeat units $N$ for two sets of FePt layer thicknesses $(14.5 \mathrm{~nm}$ and $29 \mathrm{~nm}$ ). The total thermal resistance can be simply written as

$$
R_{t h}=N\left(m R_{F e P t}+R_{C}+2 R_{I}\right)+R_{I n-A u}+R_{I n-S i}+m R_{F e P t},
$$

where $N=1,2,3,5$, and $10 ; m=1,2$; and $R_{F e P t}, R_{C}, R_{I}$, $R_{I n-A u}$, and $R_{I n-S i}$ are the thermal resistances of $14.5 \mathrm{~nm}$ thick FePt layer, $1 \mathrm{~nm}$ thick $\mathrm{C}$ layer, interface between FePt and $\mathrm{C}$ layers, interface between $\mathrm{FePt}$ and $\mathrm{Au}$ layers, and interface between FePt layers and Si substrates, respectively. As seen in Figure 3, the total thermal resistance is linearly dependent on the number of repeats $N$ for both two sets of stack samples. The slope gives us the thermal resistance of the $\mathrm{FePt} / \mathrm{C}$ unit. When converted to thermal conductivity values, these values give $k_{t h}$ of $1.8 \pm 0.2 \mathrm{~W} / \mathrm{m}-\mathrm{K}$ and $3.0 \pm 0.4 \mathrm{~W} / \mathrm{m}-\mathrm{K}$ for $\mathrm{FePt}_{14.5 \mathrm{~nm}} / \mathrm{C}_{1 \mathrm{~nm}}$ and $\mathrm{FePt}_{29 \mathrm{~nm}} / \mathrm{C}_{1 \mathrm{~nm}}$, respectively. The thermal resistance of $14.5 \mathrm{~nm}$ FePt layer $\left(R_{F e P t}\right)$ and the collective thermal resistance of the carbon layer and its associated interfaces $\left(R_{C}+2 R_{I}\right)$ can be obtained by solving the unknowns from the two slope values. $R_{F e P t}$ is equal to $1.7 \pm 1.5 \mathrm{~K}-\mathrm{m}^{2} / \mathrm{GW}$ and $\left(R_{C}+2 R_{I}\right)$ is equal to

TABLE I. List of stack thicknesses and measured effective $k_{t h}$ of the samples.

\begin{tabular}{lcc}
\hline \hline Sample & $\begin{array}{c}\text { Stack thickness } \\
L(\mathrm{~nm})\end{array}$ & $\begin{array}{c}\text { Effective thermal } \\
\text { conductivity } k_{t h}(\mathrm{~W} / \mathrm{m}-\mathrm{K})\end{array}$ \\
\hline $1 \mathrm{~N} 1$ & 30 & $0.92 \pm 0.05$ \\
$1 \mathrm{~N} 2$ & 45.5 & $1.10 \pm 0.08$ \\
$1 \mathrm{~N} 3$ & 61 & $1.32 \pm 0.10$ \\
$1 \mathrm{~N} 5$ & 92 & $1.35 \pm 0.10$ \\
$1 \mathrm{~N} 10$ & 169.5 & $1.56 \pm 0.16$ \\
$2 \mathrm{~N} 1$ & 59 & $1.89 \pm 0.09$ \\
$2 \mathrm{~N} 5$ & 179 & $2.4 \pm 0.2$ \\
$2 \mathrm{~N} 10$ & 329 & $2.8 \pm 0.3$ \\
\hline \hline
\end{tabular}

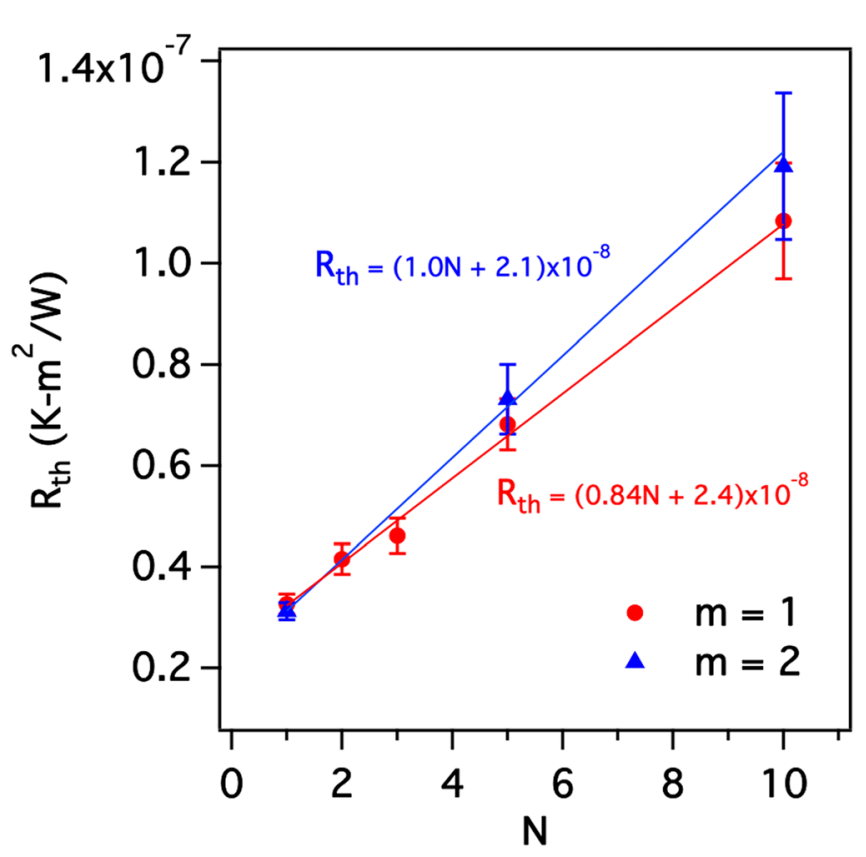

FIG. 3. Total thermal resistance $R_{t h}$ versus number of repeat units $N$ for two sets of samples. The linear lines are the weighted least square fitting.

$6.7 \pm 2.2 \mathrm{~K}-\mathrm{m}^{2} / \mathrm{GW}$. Dividing the FePt layer thickness $(14.5 \mathrm{~nm})$ and $\mathrm{C}$ layer thickness $(1 \mathrm{~nm})$ by their corresponding thermal resistance, the thermal conductivity $k_{t h}$ of $\mathrm{FePt}$ layer is therefore $8.5 \pm 7.5 \mathrm{~W} / \mathrm{m}-\mathrm{K}$ and that of amorphous $\mathrm{C}$ layer is $0.15 \pm 0.05 \mathrm{~W} / \mathrm{m}-\mathrm{K}$.

The $\mathrm{C}$ interlayer has a much smaller $k_{t h}$ than the FePt layer. Our measured value of the $\mathrm{C}$ layer is consistent with prior measurements of amorphous $\mathrm{C}$ films which range from $0.2-2.2 \mathrm{~W} / \mathrm{m}-\mathrm{K}$, depending on its mass density. ${ }^{27}$ Heat conduction across the $\mathrm{FePt} / \mathrm{C}$ interface is likely dominated by phonons since $\mathrm{C}$ is non-metallic. The two $\mathrm{C} / \mathrm{FePt}$ thermal boundary resistances $\left(2 R_{I}\right)$ are grouped into this value, resulting in an even lower $k_{t h}$ for $\mathrm{C}$. Due to the low thermal resistance of $\mathrm{FePt}$, as compared to $\mathrm{C}$ in the film stack, the measurement becomes insensitive to the thermal conductivity of FePt, leading to significant uncertainty. The impedance of the $\mathrm{FePt} / \mathrm{C}$ stack samples mostly stems from the amorphous $\mathrm{C}$ layer and its boundaries. That explains a decrease in thermal conductivity of $\mathrm{FePt} / \mathrm{C}$ from $3.0 \pm 0.4 \mathrm{~W} / \mathrm{m}-\mathrm{K}$ to $1.8 \pm 0.2 \mathrm{~W} / \mathrm{m}-\mathrm{K}$ when FePt layer thickness is reduced from $29 \mathrm{~nm}$ to $14.5 \mathrm{~nm}$. It also implies that FePt-C granular media with smaller grain size will have lower lateral thermal conductivity in the film plane due to the presence of more $\mathrm{FePt} / \mathrm{C}$ interfaces per unit length. From our results, the crossplane thermal conductivity of FePt is $4.6 \pm 4.1$ times higher than the in-plane thermal conductivity of FePt-C granular system of $14.5 \mathrm{~nm}$ grain size. We speculate that the crossplane conductivity of FePt-C could be as high as that of FePt. For media in the tetrabit/in ${ }^{2}$ regime, the FePt grain size will be even smaller than $8 \mathrm{~nm}$. Under these circumstances, heat conduction in the FePt-C granular media would be even more anisotropic, with an anisotropy higher than 10, based on our results. From the standpoint of media design, this anisotropic nature of heat conduction minimizes the lateral spreading of the temperature profile during the writing process. The large temperature gradient in both cross-track and 
down-track directions offers a sharp switching field that benefits signal-to-noise ratio.

We note that the FePt layers in our sample are in the disordered FCC state, even though in real HAMR media FePt must be a very well ordered $\mathrm{L} 1_{0}$ structure to harness its high magnetocrystalline anisotropy. ${ }^{28}$ The $k_{t h}$ of the $\mathrm{L} 1_{0}$ state is expected to be moderately larger than that of the disordered FCC state. ${ }^{29}$ Since the $\mathrm{C}$ boundaries are found to be the predominant thermal resistance, our results for disordered $\mathrm{FePt}$ thin films should still be generally applicable to the $\mathrm{L} 1_{0}$ ordered case.

In summary, we have developed a model experimental system to quantitatively determine the lateral thermal conduction in the FePt-C granular media for HAMR applications. The thermal boundary resistance of $\mathrm{C}$ is shown to be dominant in the in-plane thermal resistance of the media, which will lead to an increase in thermal resistance as smaller grain media are realized. It has been found that heat conduction in FePt-C granular media with $14.5 \mathrm{~nm}$ grain size exhibits anisotropic thermal conductivity by a factor of $4.6 \pm 4.1$ compared to along a lateral direction. This experimental model can be employed to further study the effect of segregant material choices and grain boundary thicknesses on lateral heat conduction in HAMR media.

This research was supported in part by the Data Storage Systems Center at Carnegie Mellon University and its industrial sponsors. J.A.M. and W.-L.O. acknowledge partial support from the AFOSR Young Investigator Program (FA95501110030). W.-L.O. further acknowledges partial support from the Steinbrenner and Northrop-Grumman Fellowships. The authors would also like to thank many helpful discussions with engineers from Seagate Technology, Western Digital, and HGST - a WD company. H.H. thanks Dr. Steven D. Granz for providing some sputtering recipes.

${ }^{1}$ D. Weller, O. Mosendz, G. Parker, S. Pisana, and T. S. Santos, Phys. Status Solidi A 210, 1245 (2013).

${ }^{2}$ H. Yuan, A. Chernyshov, J. Mardinly, K. Srinivasan, R. Acharya, G. Bertero, and T. Yamashita, J. Appl. Phys. 109, 07B772 (2011).
${ }^{3}$ L. Zhang, Y. K. Takahashi, K. Hono, B. C. Stipe, J.-Y. Juang, and M. Grobis, J. Appl. Phys. 109, 07B703 (2011).

${ }^{4}$ A. Q. Wu, Y. Kubota, T. Klemmer, T. Rausch, P. Chubing, P. Yingguo, D. Karns, Z. Xiaobin, D. Yinfeng, E. K. C. Chang, Z. Yongjun, Z. Hua, G. Kaizhong, J. U. Thiele, M. Seigler, J. Ganping, and E. Gage, IEEE Trans. Magn. 49, 779-782 (2013).

${ }^{5}$ M. H. Kryder, E. C. Gage, T. W. McDaniel, W. A. Challener, R. E. Rottmayer, J. Ganping, H. Yiao-Tee, and M. F. Erden, Proc. IEEE 96, 1810 (2008).

${ }^{6}$ A. F. Torabi, J. van Ek, E. Champion, and J. Wang, IEEE Trans. Magn. 45, 3848 (2009).

${ }^{7}$ J. G. Zhu and L. Hai, IEEE Trans. Magn. 49, 765 (2013).

${ }^{8}$ D. Karns, G. Ju, A. Itagi, and B. Lu, in Proceedings of Intermag (2008).

${ }^{9}$ A. Perumal, Y. K. Takahashi, and K. Hono, Appl. Phys. Express 1, 101301 (2008).

${ }^{10}$ O. Mosendz, S. Pisana, J. W. Reiner, B. Stipe, and D. Weller, J. Appl. Phys. 111, 07B729 (2012).

${ }^{11}$ J. F. Hu, T. J. Zhou, W. L. Phyoe, K. Cher, and J. Z. Shi, IEEE Trans. Magn. 49, 3737 (2013).

${ }^{12}$ T. Matsumoto, F. Akagi, M. Mochizuki, H. Miyamoto, and B. Stipe, Opt. Express 20, 18946 (2012).

${ }^{13}$ R. Fernandez, D. Teweldebrhan, C. Zhang, A. Balandin, and S. Khizroev, J. Appl. Phys. 109, 07B763 (2011).

${ }^{14}$ J. P. Feser and D. G. Cahill, Rev. Sci. Instrum. 83, 104901 (2012).

${ }^{15}$ P. E. Hopkins, J. R. Serrano, L. M. Phinney, S. P. Kearney, T. W. Grasser, and C. T. Harris, J. Heat Transfer 132, 081302 (2010).

${ }^{16}$ J. A. Malen, K. Baheti, T. Tong, Y. Zhao, J. A. Hudgings, and A. Majumdar, J. Heat Transfer 133, 081601 (2011).

${ }^{17}$ K. T. Regner, D. P. Sellan, Z. Su, C. H. Amon, A. J. H. McGaughey, and J. A. Malen, Nature Commun. 4, 1640 (2013).

${ }^{18}$ K. T. Regner, S. Majumdar, and J. A. Malen, Rev. Sci. Instrum. 84, 064901 (2013).

${ }^{19}$ A. J. Schmidt, R. Cheaito, and M. Chiesa, Rev. Sci. Instrum. 80, 094901 (2009).

${ }^{20}$ S. D. Granz and M. H. Kryder, IEEE Trans. Magn. 48, 2746 (2012).

${ }^{21}$ D. G. Cahill, Rev. Sci. Instrum. 75, 5119 (2004).

${ }^{22}$ M. Asheghi, K. Kurabayashi, R. Kasnavi, and K. E. Goodson, J. Appl. Phys. 91, 5079 (2002).

${ }^{23}$ J. Buschbeck, S. Fahler, M. Weisheit, K. Leistner, J. McCord, B. Rellinghaus, and L. Schultz, J. Appl. Phys. 100, 123901 (2006).

${ }^{24}$ C. J. Smithells, Metals Reference Book, 6th ed. (Butterworths, London, 1983).

${ }^{25}$ D. R. Lide, CRC Handbook of Chemistry and Physics, 86th ed. (CRC Press, Baco Raton, 2005).

${ }^{26}$ S. R. P. Silva, Properties of Amorphous Carbon (INSPEC, London, 2003).

${ }^{27}$ A. J. Bullen, K. E. O'Hara, D. G. Cahill, O. Monteiro, and A. v. Keudell, J. Appl. Phys. 88, 6317 (2000).

${ }^{28}$ H. Ho, E. Yang, D. E. Laughlin, and J.-G. Zhu, Appl. Phys. Lett. 102, 112411 (2013).

${ }^{29}$ J. C. Duda, T. S. English, D. A. Jordan, P. M. Norris, and W. A. Soffa, J. Phys.: Condens. Matter 23, 205401 (2011). 